\title{
The health of Swiss adolescents and its implications for training of health professionals in Switzerland
}

\begin{abstract}
Swiss adolescents generally enjoy satisfying life conditions. Nonetheless, violence, suicide and mental health are the main concerns together with injuries, chronic conditions and eating disorders. Adolescents still face barriers to access the care they need. Adequate training can improve practitioners' skills when dealing with adolescents. The last two decades have seen the development of innovative adolescent health units and networks in various regions of Switzerland as well as research and public health programmes. Training programmes in adolescent health (continuous medical education, post-graduate or pre-graduate) for physicians and nurses are developing but still patchy in Switzerland. Adolescent health is not a sub-specialty as such. Efforts have to be made in order to link with professional associations and institutions to implement adolescent health curricula more efficiently.
\end{abstract}

Keywords: adolescent health; health professionals; training.

DOI 10.1515/ijamh-2016-5019

Received January 15, 2015; accepted March 4, 2015; previously published online June 30, 2015

\section{Introduction}

Switzerland is a small country with high diversity. Four national languages and a democratic governmental structure allow each canton to have autonomy and selfdetermination. Primary healthcare is mainly based on private practices (pediatricians, general practitioners or general internists). The Swiss population has in general

*Corresponding author: Anne Meynard, MD, Unité Santé Jeunes, Division of General Paediatrics, Department of Paediatrics, Geneva University Hospitals, 87 Bvd de la Cluse, 1211 Geneva, Switzerland, E-mail: anne.meynard@hcuge.ch

Christoph Rutishauser: University Children's Hospital, Zurich, Switzerland

Mirjam Thomi: Institute of Nursing Science, Inselspital, Department of Pediatrics, University Hospital Bern, Bern, Switzerland and University of Basel, Basel, Switzerland

Suzanne M. Stronski Huwiler: School Medical Service, Zurich, Switzerland easy access to primary care and also to specialized care especially in urban areas with a universal health coverage insurance system. Young people have good access to health care with more than $75 \%$ of young people seeing a primary care practitioner every year $(1,2)$. Adequate training of health professionals is an essential part of quality care delivery for adolescents with good evidence that training can improve practitioners' skills when dealing with adolescents $(3,4)$. The last three decades saw the development of innovative training programmes in adolescent health in all regions of the world also greatly supported by the World Health Organization $(5,6)$. According to these programmes and recent developments of medical education, there is also good evidence that a well-designed curriculum can improve learning outcomes: define the main issues to teach; adapt training goals and objectives to the needs of learners and to the local epidemiological situation; and use interactive teaching techniques. Evaluation not only of training but also of implementation processes is crucial to ensure sustainability and appropriateness of training programmes. Continuous education and training of trainers are needed to ensure capacity building of a pool of effective trainers. The aim of this article is to describe milestones of adolescent health training development as well as raising issues that have to be considered in improving training of health professionals in this field in Switzerland.

\section{The health of Swiss adolescents: identifying and adapting training to the health needs of adolescents}

Switzerland has developed innovative public health and clinical programmes in the late 1980s and early 1990 s to address addictions as well as sexually transmitted infections (STI) as a response to open drug scenes and emergence of human immunodeficiency virus infections. While these programmes did not target young people only, they could explain that research on young people's health behaviours especially around substance use and STI was encouraged. Switzerland is a member of the 
Health behavior in school health children survey (HBSC) since 1986 (7). The Swiss Multicentric Adolescent Survey on Health (SMASH) was the first school-based survey interviewing a nationally representative sample of older adolescents (16-20 years old) both in schools and vocational training. The two waves of the survey $(1993,2002)$ contributed to a better understanding of the health needs of young Swiss people in addition to HBSC and other epidemiological surveys (8).

According to SMASH and HBSC, Swiss adolescents usually describe themselves as healthy, having a high level of life satisfaction and enjoying a satisfying school atmosphere. Due to a favourable socioeconomic situation, they have been protected from the effects of economic crisis and unemployment rates stay low (9). The main areas of concern are injuries and violence or suicide, mental health problems including eating disorders, chronic conditions and substance use as in many western European countries. The rate of STI and adolescent pregnancy is low compared to other Western European countries or the USA. Rates of obesity among Swiss adolescents are stable and lower than in other European countries (10). Vaccination rates among Swiss adolescents are highly variable: cantons with a structured school health programme have higher adolescent vaccination rates for all vaccines, great regional differences in parental refusal especially regarding measles and hepatitis B (11-13). Social conditions play a crucial role: hence a growing proportion of adolescents have difficult life conditions that impact on their health and development as well as their access to health care.

\section{Responding to adolescent's health needs: 20 years of adolescent health and training in Switzerland}

The Swiss Association for Adolescent Health (www.sggaassa.ch) was founded in 1991 after the first International Congress of the International Association for Adolescent Health was held in Montreux, Switzerland. A small group of professionals from all regions of Switzerland started developing research, public health and clinical care programmes.

In 1998, the first adolescent academic unit with professorship in Europe was founded in Lausanne, Switzerland. At the same time other teaching hospitals set up adolescent health academic units with multidisciplinary clinical care, research and training mandates (Lausanne, Geneva, Zurich and the Eastern Switzerland
Network in St. Gallen). Other teaching hospitals, without having specific adolescent health programmes, have shown interest in training paediatric residents about adolescent health issues.

\section{Training opportunities in Switzerland}

Training needs analysis of in-service health professionals (14-16) provided useful data to develop various training curricula: continuous medical education (CME) for physicians and other health professionals, post-graduate training programmes for pediatric and family medicine residents as well as integration of adolescent health topics in pre-graduate curricula for medical doctors and nurses. As per the initiative of the Multidisciplinary Unit for Adolescent Health in Lausanne, a joint initiative of Swiss and European health professionals EUropean Training in Effective Care and Health (EuTEACH) was launched in 1998 with the development of training material, a website with freely accessible training material (www.euteach. com) as well as a yearly 1 week summer school (6). Since 2002, around 300 health professionals (from various disciplines and countries) have attended the summer school for continuous education. The EuTEACH program does not deliver basic clinical courses in adolescent health; rather it targets professionals already knowledgeable in adolescent health and holding teaching positions. At the postgraduate level, various initiatives have been implemented locally. The Swiss Association for Adolescent Health, at the request of the Swiss Paediatric Society developed a 2-day post-graduate training programme for paediatric residents that ran from 2006 to 2012. In total, 75 paediatric residents mostly from the German part of Switzerland were trained. This training addressed core components of adolescent health. No formal evaluation was done. The Swiss Association for Adolescent Health also runs a yearly national conference.

Swiss post-graduate curricula in paediatrics and general practice contain training objectives in adolescent health but these are often scattered across various fields with no comprehensive approach, as it is not recognized as a sub-specialty of any discipline.

At pre-graduate level, competency-based approaches are being developed for the training of all health professionals in Switzerland. For medical students a federal examination is conducted based on a common catalogue of learning objectives (17), but not for other health professionals (nurses, midwives, dieticians, etc.) (18). The 
academic adolescent units described earlier and maybe others have implemented adolescent health objectives and trainings both at bachelor and master levels (medical and other health professionals). In Geneva and Lausanne, adolescent-simulated patient programmes have been developed for pre-graduate, post-graduate and CME needs (16, 19-21). The regular review of learning objectives for medical students and the national framework for other health professionals are opportunities to advocate for better integration of adolescent health issues in the existing curricula.

For the time being, in Switzerland, adolescent health does not figure as a stand-alone sub-specialty as it does in North America despite clinical and research opportunities and fellowships in Switzerland. Professionals complete their training going abroad (USA, Australia or Canada). In France, the "Diplome Inter-universitaire en Medecine et Sante de l'adolescent" (22) is an opportunity for Frenchspeaking clinicians (physicians, nurses or other health professionals) to get a basic clinical training based on a holistic approach of adolescent health.

Adolescent health is an important topic in the postgraduate and CME training of gynaecologists, child and adolescent psychiatrists and other health professionals, often with a specialist, disease-focused approach.

\section{The role of the Swiss Association for Adolescent Health}

Some domains could be pushed forward:

- replication of the training course for paediatric residents as a post-graduate interdisciplinary training proposition for residents and nurses based on the EuTEACH model;

- linking with the main professional associations of physicians and nurses to implement this offer;

- advocate for the implementation of regional health networks using existing Swiss examples as case studies.

\section{A strong youth-friendly primary care}

Primary care, in Switzerland represented by general paediatricians, general practitioners and general internists is in an ideal position to respond to the needs of most adolescents in a continuum from child to adulthood but has not yet fully reached this goal. The recent setting-up of a professional association for family medicine and institutes or units for family medicine in the five Swiss universities is pushing forward better research in primary care as well as academic recognition of general practice. Interdisciplinary collaboration especially between physicians and nurses is encouraged. Vertical implementation of pregraduate training in generic skills - communication skills (i.e., motivational interviewing, shared decision-making), preventive care, supporting self-management for patients with chronic condition or special healthcare needs as well as collaborative care is ongoing but core competencies in adolescent health are often not included. Adolescent health specialists currently use this opportunity to develop innovative research or training programmes (23).

Adolescents have easy access to primary care but some major barriers are still not addressed: breach in confidentiality for minors or young adults because of the billing system; expensive insurance system for young adults; lack of recognition of young people's health needs in a comprehensive approach; and lack of effective reimbursement system as incentive for primary care professionals.

\section{Strong regional networks: adolescents with special needs and hospital care}

The hospital-based outpatient adolescent units provide integrated multidisciplinary care for adolescents with chronic conditions or disabilities and adolescents with complex health or psychosocial needs in collaboration with hospital specialists and the external network. Some paediatric hospital wards have integrated "youth-friendly criteria". These clinics have developed formal or informal networks of collaboration with local partners and have areas of expertise (i.e., chronic conditions, functional disorders, eating disorders, migrant care). Transition and patient education programmes for youth with chronic conditions start to integrate core adolescent health concepts in their programmes (24). Advocacy, continuity of care for adolescents and young adults and coherence of interventions for complex situations (case management) are crucial domains to be pushed forward.

\section{School health}

Adolescent health and school health are closely linked. Large cities and some cantons have very effective school 
health services, while others have very limited resources. In 2014, the World Health Organization published a European framework for quality standards in school health services and competences for school health professionals (25). It can be used as a basis to develop training programmes tailored to country needs. Currently one canton (Zurich) is developing a school health curriculum for medical doctors based on this framework (WHO school Health).

\section{Conclusion}

Switzerland has an active and productive group of professionals developing quality clinical care, research and training programmes in adolescent health.

Training curricula constantly need new adaptation for health professionals to be well prepared to face new challenges. Over the last 10 years, generic skills training of doctors and nurses (communication, interdisciplinary collaboration, networking, integration of prevention in care) has improved. This could also have an effect on healthcare delivery to adolescents, as these are core skills in this discipline if adapted to the adolescent population. The main challenges in improving training of health professionals in adolescent health in Switzerland are:

- Advocating for adolescent health in a country where the ageing of the population and chronic conditions are now the main focus of most research and training programmes for nurses and physicians (pre-graduate, post-graduate and CME).

- Encouraging interprofessional collaboration and regional networks to improve the care of adolescents with special health needs.

- Creating a multidisciplinary working group through the Swiss Association for Adolescent Health for the development of a coherent training curriculum adapted to various specialties.

\section{References}

1. Haller DM, Michaud PA, Suris JC, Jeannin A, Narring F. Opportunities for prevention in primary care in a country with universal insurance coverage. J Adolesc Health 2008;43:517-9.

2. Meynard A, Haller DM, Navarro C, Narring F. Prises de risque a l'adolescence: strategies et outils pour les consultations en medecine de premier recours. Rev Med Suisse 2008;4:1451-5. [French].

3. Sanci LA, Coffey CM, Veit FC, Carr-Gregg M, Patton GC, et al. Evaluation of the effectiveness of an educational intervention for general practitioners in adolescent health care: randomised controlled trial. Br Med J 2000;320:224-30.

4. Ford CA, Millstein SG, Halpern-Felsher BL, Irwin CE, Jr. Influence of physician confidentiality assurances on adolescents' willingness to disclose information and seek future health care. A randomized controlled trial. J Am Med Assoc 1997;278:1029-34.

5. Sanci L, Glover S, Coffey C. Adolescent health education programmes: theoretical principles in design and delivery. Ann Acad Med Singapore 2003;32:78-85.

6. Michaud PA, Stronski S, Fonseca H, Macfarlane A. The development and pilot-testing of a training curriculum in adolescent medicine and health. J Adolesc Health 2004;35:51-7.

7. Health behavior in school-aged children. Accessed 01 February 2015. Available at: http://www.hbsc.ch.

8. Narring F, Michaud PA. Methodological issues in adolescent health surveys: the case of the Swiss Multicenter-adolescent survey on health. Soz Praventivmed 1995;40:172-82.

9. UNICEF. Children of the recession: the impact of the economic crisis on child well-being in rich countries. Florence: Innocenti Report Card 12, UNICEF Office of Research, 2014.

10. Michaud PA, Ambresin AE. La sante des adolescents en Suisse. Praxis 2013;102:1111-6.

11. Jeannot E, Wyler CA, Meynard A, Kaiser B, Sudre P, et al. Facteurs associes a la vaccination HPV chez les jeunes filles de 13 a 14 ans dans le canton de Geneve, Suisse. Rev Epidemiol Sante Publique 2013;61:513-18.

12. Lang P, Zimmermann H, Piller U, Steffen R, Hatz C. The Swiss national vaccination coverage survey, 2005-2007. Public Health Rep 2011;126:97-108.

13. Lang PU, Hatz Ch. Couverture vaccinale des enfants ages de 2, 8 et 16 ans en Suisse, 2008-2010. Bulletin OFSP 2012;40:681-6.

14. Kraus B, Stronski S, Michaud PA. Training needs in adolescent medicine of practising doctors: a Swiss national survey of six disciplines. Med Educ 2003;37:709-14.

15. Haller DM, Meynard A, Duperrex O. Delphi method to identify the gaps in adolescent health training in a family medicine postgraduate curriculum. Int J Child Adolesc Health 2008;1:33-9.

16. Caflisch M. Medecine des adolescents. Paediatrica 2006;17:66-7.

17. Michaud PA. Reforms of the pre-graduate curriculum for medical students: the Bologna process and beyond. Swiss Med Wkly 2012;142:w13738.

18. Ledergerber MJ, Sottas B. Projet competences finales pour les professions de la sante HES. Conference des Recteurs des Hautes Ecoles Specialisees Suisses, 2009.

19. Meynard A, Navarro C, Cerutti B, Haller G, Nu V, et al. A workshop with simulated adolescent patients to teach clinical skills to 4 th year medical students: students and facilitators' views. Annual Congress SSP 2013, Geneva: Switzerland, 20-21 June 2013.

20. Meynard A, Szynalski M, Vu N, Navarro C, Narring F. Teaching basic interviewing skills to medical and nursing students using simulated adolescent patients: opportunities for an interprofessional education module? Annual Congres SSP 2013, Geneva: Switzerland, 20-21 June 2013.

21. Haller DM, Meynard A, Lefebvre D, Tylee A, Narring F, et al. Brief intervention addressing excessive cannabis use in young people consulting their GP: a pilot study. $\mathrm{Br}$ J Gen Pract 2009;59:166-72.

22. Diplome Inter Universitaire en Medecine et Sante de l'Adolescent. Available at: http://medecine-pharmacie.univ- 
rouen.fr/diu-medecine-et-sante-de-l-adolescent-351503.kjsp. Accessed on May 20, 2015.

23. Haller DM, Meynard A, Lefebvre D, Ukoumunne OC, Narring F, et al. Effectiveness of training family physicians to deliver a brief intervention to address excessive substance use among young patients: a cluster randomized controlled trial. Can Med Assoc J 2014;186:E263-72.
24. Rutishauser C, Sawyer SM, Ambresin AE. Transition of young people with chronic conditions: a cross-sectional study of patient perceptions before and after transfer from pediatric to adult health care. Eur J Pediatr 2014;173:1067-74.

25. World Health Organization. European framework for quality standards in school health services and competences for school health professionals. Geneva: WHO, 2014. 